\title{
INVESTIGATION OF MAGNETIC PROPERTIES FOR DIFFERENT COIL SIZES OF DYNAMIC WIRELESS CHARGING PADS FOR ELECTRIC VEHICLES (EV)
}

\author{
Syasya Azra Zaini, Siti Hajar YusofF*, Amira Aziera Abdullah, \\ SHEROZ KHAN, FARIDAH ABD RAHMAN AND NADIA NAZIEHA NANDA \\ Department of Electrical and Computer Engineering, Faculty of Engineering, \\ International Islamic University Malaysia, \\ P.O Box 10, 50728 Kuala Lumpur, Malaysia \\ *Corresponding author: sitiyusoff@iium.edu.my
}

(Received: $14^{\text {th }}$ March 2019; Accepted: $22^{\text {nd }}$ October 2019; Published on-line: $20^{\text {th }}$ January 2020)

\begin{abstract}
Electric vehicles (EV) have been introduced in the recent years due to public awareness of the effect of gas emission from traditional cars and the extinction of petroleum natural resources. For charging EV, dynamic wireless charging is considered in this paper. This is because it is more convenient and saves charging time since it charges the electric vehicle while moving. The main challenge of this process is to maintain a high amount of power transfer from primary to secondary coil. One of the factors contributing to a good power transfer is the size of the coil [1]. There are various designs of coil for wireless charging of electric vehicles (EV). Among the most common designs are circular pad (CP), rectangular pad (RP), double-D pad (DDP), and double-D quadrature pad (DDQP). In this paper, circular pad (CP) is chosen for use, due to its simplicity in design and good electrical and magnetic properties. Three different coil pair sizes are tested to find the most suitable coil pair for the primary and secondary pads that has the maximum power transfer and is least sensitive to misalignment. The magnetic properties have been investigated to obtain the highest value of magnetic flux. The geometry design of the pads and simulation was done using COMSOL Multiphysics software. From the simulation, it was found that the unsymmetrical coil pair gives high magnetic strength when the outer diameters of the primary and secondary coils have the same value.
\end{abstract}

ABSTRAK: Kenderaan Elektrik (EV) telah diperkenalkan sejak beberapa tahun ini hasil kesedaran awam tentang kesan pembebasan gas dari kenderaan lama dan pengurangan sumber asli petroleum. Kajian ini berkaitan pengecas dinamik tanpa wayar bagi mengecas EV. Ini kerana pengecas ini lebih sesuai dan jimat masa mengecas kerana kenderaan elektrik dicas ketika bergerak. Cabaran utama proses ini adalah mengekalkan pemindahan tenaga yang tinggi daripada gegelung primer kepada gegelung sekunder. Salah satu faktor bagi mendapatkan pemindahan tenaga yang tinggi adalah saiz gegelung wayar [1]. Terdapat pelbagai bentuk gegelung bagi mengecas kenderaan elektrik (EV) tanpa wayar. Antaranya adalah pad membulat (CP), pad segiempat tepat (RP), pad berganda-D (DDP), dan pad kuadratur berganda-D (DDQP). Kajian ini telah menggunakan pad membulat (CP) kerana reka bentuknya yang ringkas dan ia mempunyai sifat elektrikal dan magnatik yang baik. Tiga pasang gegelung berbeza telah diuji bagi mendapatkan pasangan gegelung pad primer dan sekunder yang paling sesuai di mana ianya mempunyai pemindahan tenaga maksima dan paling kurang sensitif pada ketidakjajaran. Sifat magnet telah diuji bagi mendapatkan nilai fluks magnet tertinggi. Rekabentuk geometri pad dan simulasi telah dijalankan menggunakan perisian Multifizik COMSOL. Hasil simulasi mendapati pasangan gegelung yang tidak simetri telah menghasilkan kekuatan magnetik tertinggi apabila diameter luaran gegelung primer dan sekunder mempunyai nilai sama. 
KEYWORDS: eletric vehicle (EV); magnetic properties; wireless power transfer; inductive charging; circular coil

\section{INTRODUCTION}

Electric vehicles (EV) have been introduced in 2012 due to public awareness of the effect of gas emission from traditional cars and the extinction of petroleum natural resources [2]. Malaysia's government also supports electric vehicles by offering full exemption of tax for EV. Besides, the fact that EV and plug-in hybrid EV produce smaller carbon dioxide $\left(\mathrm{CO}_{2}\right)$ than traditional vehicles and lower the cost of ownership over lifetimes has attracted manufacturers and researchers alike to study more about this topic [3]. In developed countries, EV sales are rising rapidly due to their advantages.

In wireless charging systems, several components are needed to ensure that power is transferred efficiently from the grid to the car battery, as shown in Fig. 1. The wireless charging process will begin from the DC input, which is the main source power. Then, the $\mathrm{DC}$ power will pass through an inverter and compensation to convert it from $\mathrm{DC}$ to $\mathrm{AC}$ power. For wireless charging, the transmitter coil and receiver coil are used as a medium to transmit and receive power using an air gap channel. After that, the received power will go through the same process with the help of a converter before reaching the car battery. Many types of converter can be used, such as AC/AC matrix converters [4,5], T-type direct converters, and many more.

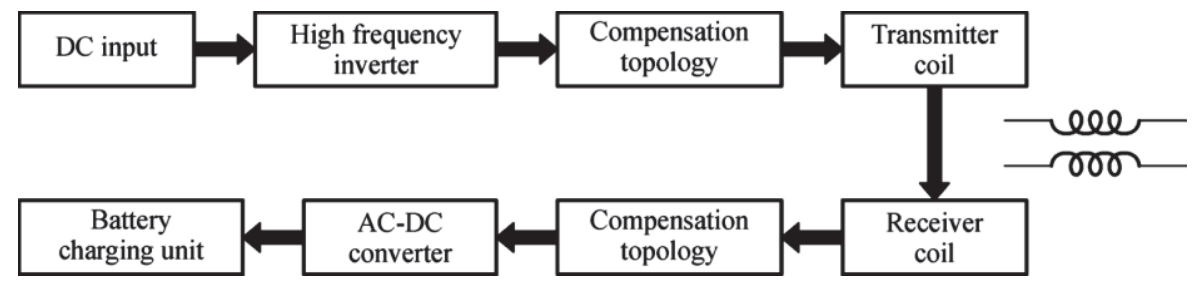

Fig. 1: Basic block diagram of wireless charging EV system [6].

There are various designs of coil for the wireless charging of electric vehicles (EV). Among the most common design are circular pad (CP), rectangular pad (RP), double-D pad (DDP), and double-D quadrature pad (DDQP) [7,8]. Each of the pad designs has its own benefit for its specific requirements and applications. Among the designs are:

\section{a) Circular Pad (CP)}

Circular pad design is the most widely used due to its simplicity in design and manufacturing [9]. Besides that, CP design also has good electrical and magnetic properties to transfer power efficiently [10]. In terms of misalignment, CP design has the same tolerance in all directions [8] due to its circular shape. However, researchers are still trying to reduce the misalignment effect in order to improve the performance of wireless charging. Polarized circular pads have mostly been implemented in static EV charging applications [8]. Despite that, CP has a problem with the increasing of the air gap. This is because the diameter of the coil will get four times larger when the air gap increases once. This is due to the $1: 4$ ratio of the primary flux path and diameter of coil $[8,11]$. Due to this limitation, other designs of coil were introduced. 


\section{b) Rectangular Pad (RP)}

Rectangular pad (RP) is another basic coil design for wireless charging. It is suitable in dynamic charging due to its cost effectiveness. Besides that, RP is also popular because of its capability to transfer power and its reasonable cost of materials [12]. In order to optimize the power transfer between coils, a ferrite bar has been used and attached to the rectangular coil. Wang et al. tested a variety of lengths of ferrite bar on the rectangular coil in order to improve the coupling coefficient and mutual inductance between two coils [13]. From the simulation, it can be concluded that longer ferrite bars can transfer more power than shorter bars.

\section{c) Double-D Pad (DDP)}

Besides circular and rectangular pad, Double-D pad (DDP) is also among the popular designs for wireless EV charging. This is due to a better performance and it interoperability with different secondary topologies [7]. Even though DDP has a higher tolerance of misalignment, it only covers the horizontal component. Therefore, the Double-D Quadrature pad (DDQP) was invented to have a high tolerance in both horizontal and vertical components [8]. The DDQP design is a combination of DD pad and rectangular pad (RP). This pad has high misalignment tolerance especially when it is placed at the secondary side [14]. Nonetheless, this design leads to increased costs due to the increase in number of coils. Figure 2 below shows the design of DDP and DDQP coils.

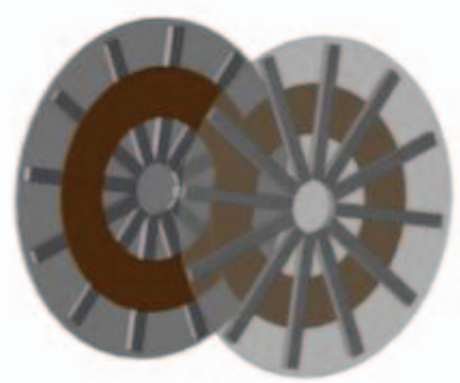

(a)

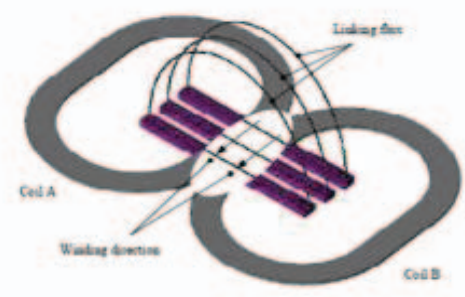

(c)

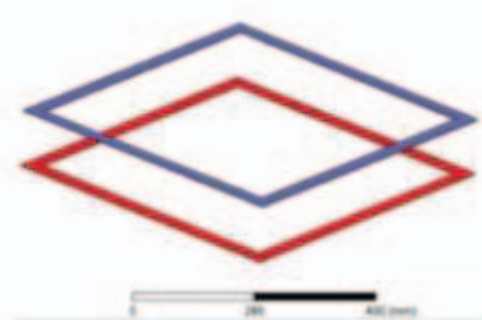

(b)

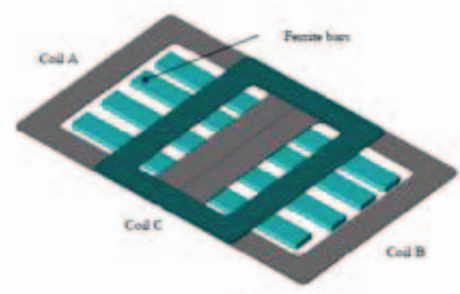

(d)

Fig. 2: Different charging pads (a) CP (b) RP (c) DDP (d) DDQP.

Among many pad designs, circular couplers are the most usable because of their magnetic properties [15]. However, different sizes of circular pad would give different performance in terms of magnetic properties. Therefore, this paper would design and discuss different pairs of circular-circular coil pads that give highest magnetic strength between the primary and secondary coils.

This paper is organized as follows: Section II presents the methodology consisting of the design for each coil pair. Then, Section III discussed the simulation results using COMSOL Multiphysics software. Finally, the paper concludes in Section IV. 


\section{METHODOLOGY}

In this project, three different circular pairs of coils have been investigated to decide which pair gives the maximum power transfer. The secondary coil, or the receiving side, is set to the same value in all three designs, while the primary, or transmitting side, is varied to compare the effect on power transfer. Proper matching of coil parameters such as the diameter of the primary and secondary coils, distance between two coils, and mutual inductance between them, allow the maximum power transmission through the link. Therefore, this paper proposed the best design for circular coils in order to obtain high magnetic strength. In all coil pairs, ' $\mathrm{P}$ ' represents the primary coil and ' $\mathrm{S}$ ' represents the secondary coil. Detailed explanations about the three different coils will be discussed below.

a) $P_{1}-\mathrm{S}$

For this type of coil, the inner diameter as well as the outer diameter of primary coil are kept smaller than the secondary coil.

b) $P_{2}-\mathrm{S}$

For this coil-pair, the inner diameter of the primary coil is kept smaller than the inner diameter of the secondary coil and the outer diameter of the primary coil is kept the same as the outer diameter of the secondary coil.

c) $P_{3}-\mathrm{S}$

For this type of coil pair, the outer diameter of primary coil is larger than secondary coil and diameter of inner primary coil is less than inner diameter of secondary coil.

Table 1 listed the value parameters that were used in this project. Figure 3 also shows a clear illustration of the three coil pairs designed. The primary coil is placed at the bottom, whereas secondary coil is placed at the top in order to replicate a real EV system. For real $\mathrm{EV}$, the primary coil is attached to the road while the secondary coil attached below the car.

Table 1: Geometry parameters of designed coils

\begin{tabular}{ccc}
\hline Coil & $\boldsymbol{D}_{\text {out }}(\mathbf{c m})$ & $\boldsymbol{D}_{\text {in }}(\mathbf{c m})$ \\
\hline$S$ & 28 & 21.4 \\
$P_{1}$ & 24 & 6 \\
$P_{2}$ & 28 & 12 \\
$P_{3}$ & 32 & 12 \\
\hline
\end{tabular}

Secondary coil

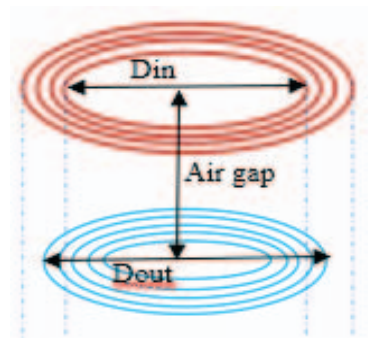

a) $P_{1}-\mathrm{S}$

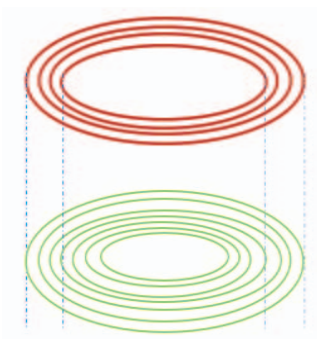

b) $P_{2}-\mathrm{S}$

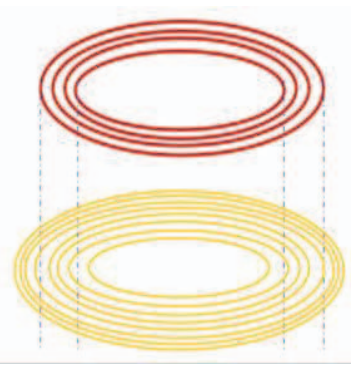

c) $P_{3}-\mathrm{S}$

Fig. 3: Different coil pairs. 
Figure 4 below shows the primary and secondary coil sketch in COMSOL Multiphysics before running the simulation. The air gap between the primary coil and secondary coil is fixed at $16 \mathrm{~cm}$.

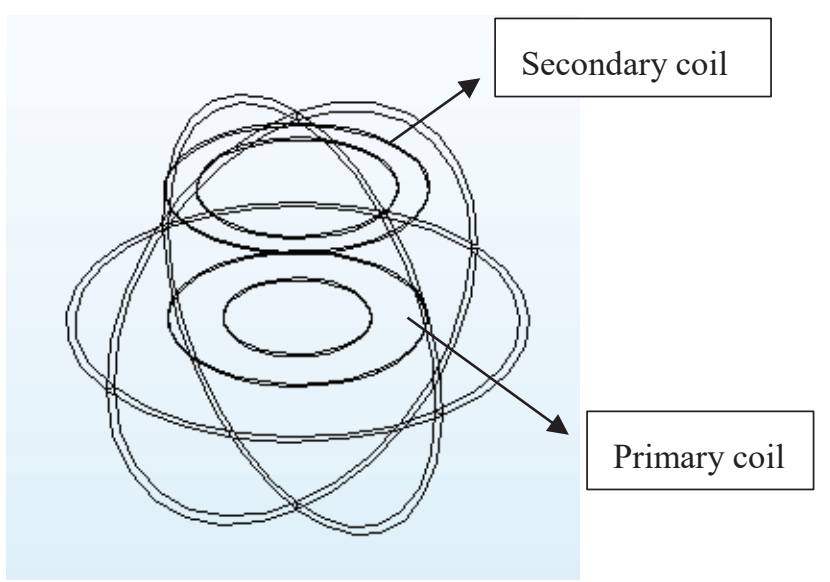

Fig. 4: Primary and secondary coil drawn in COMSOL Multiphysics.

After the simulations for all three pairs were done, another simulation is performed to vary the inner diameter while fixing the outer diameter for the best primary coil. The coil design that gives the highest magnetic field norm and magnetic flux density norm will be simulated again by varying the inner diameter of primary coil in order to find the most suitable parameter for the primary coil.

\section{SIMULATION RESULTS}

There are three designs of coil pair that were tested in the COMSOL Multiphysics software. Each coil has a fixed number of turns, N, and an air gap with no misalignment condition. The secondary coil is also fixed for all the three tests. The diameter of the secondary coil is chosen based on the best design achieved from Aditya [1]. The diameter of the primary coil is the only varying parameter for this simulation. The simulation results are shown below.

\subsection{Magnetic Field Characteristic}

In each coil pair, different values of magnetic field have been identified. The figures below show the behaviour of magnetic fields around the coils. The red colour indicates a strong magnetic field while the blue colour indicates the lowest field strength. In each simulation, there is a colour legend that states the maximum and minimum magnetic fields. Different ranges of colour show different values of magnetic field inside the coil.

Table 2 shows the magnetic field characteristics for all coil pairs. This simulation is done to observe the behaviour of the magnetic fields between the primary and secondary coils. From the simulation, it can be seen that the behaviour of the magnetic fields is quite similar for all pairs since there are no misalignments involved.

However, table 2 only shows the behaviour of the magnetic fields. In order to know the magnitude of magnetic fields, the magnetic fields norm have been simulated. The maximum normal magnetic field value for the first, second, and third pairs are $9.82 \times 10^{5}(\mathrm{~A} / \mathrm{m}), 1.0$ $\times 10^{6}(\mathrm{~A} / \mathrm{m})$ and $9.64 \times 10^{5}(\mathrm{~A} / \mathrm{m})$, respectively. Normal magnetic fields represent the magnitude for the magnetic fields between two coil pairs. Table 3 shows the magnetic field norms for each coil pair. 
Table 2: The magnetic field behaviour for each coil pair

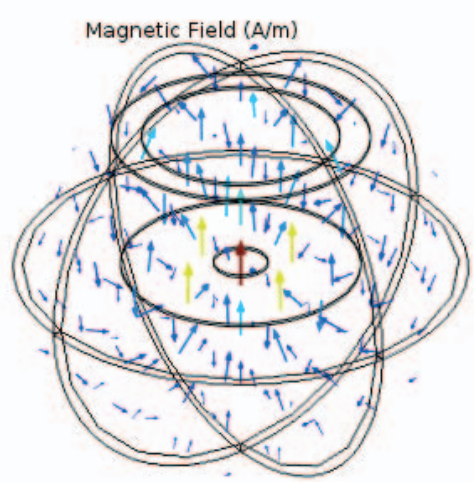

(a) $P_{1}$-S coupling

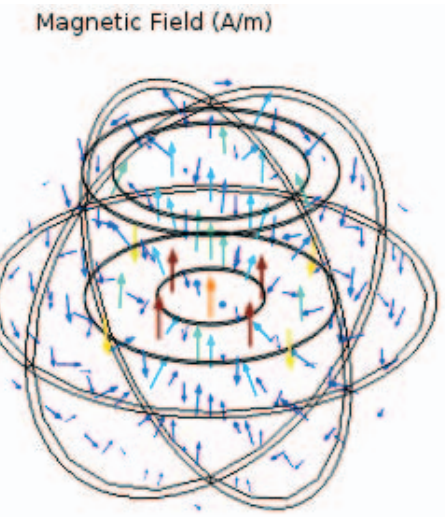

(b) $P_{2}$-S coupling

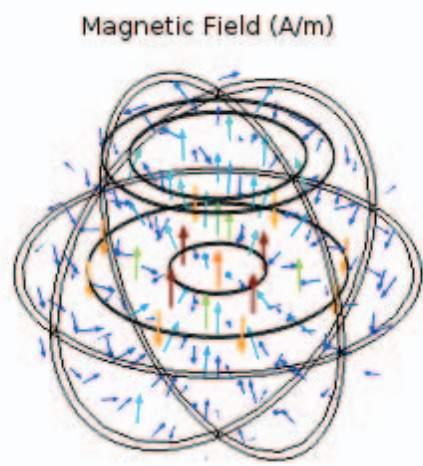

(c) $P_{3}$-S coupling
Table 3: The magnetic field norms for each coil pair

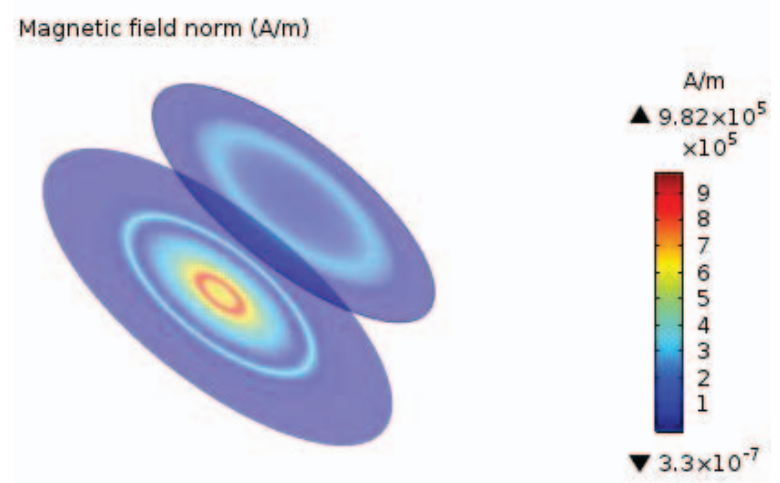

(a) $P_{1}$-S coupling

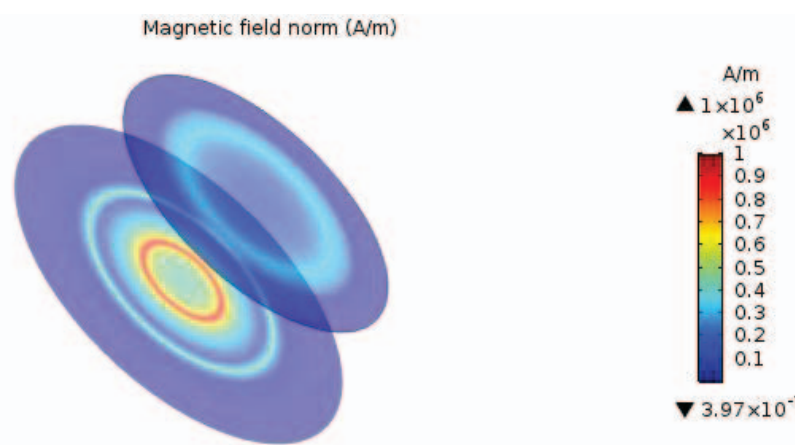

(b) $P_{2}$-S coupling
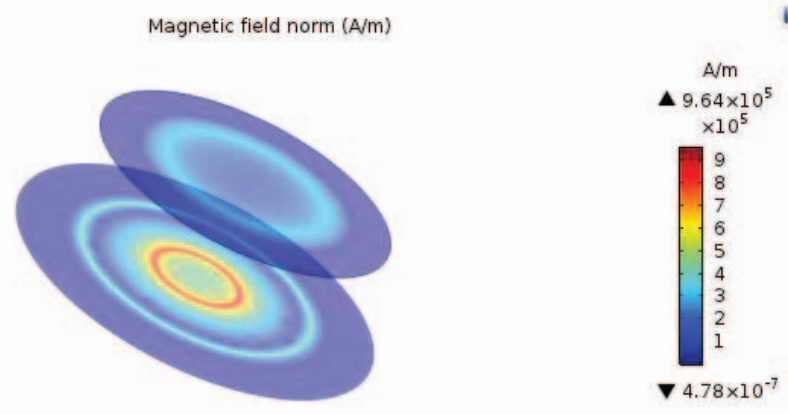

(c) $P_{3}$-S coupling

From the table above, $P_{2}-\mathrm{S}$ gives the highest magnetic field norm with $1.0 \times 10^{6} \mathrm{~A} / \mathrm{m}$. So, high magnetic strength between $P_{2}-\mathrm{S}$ coils will provide better power transfer between the primary and secondary coils. There is no specific range of magnetic field and magnetic flux density needed for good performance of wireless charging. However, a magnetic field induces electrical charge movement, producing an electric current. Therefore, a high value of magnetic field and magnetic flux density produces more current and thus improves the charging process for the electric vehicle (EV). 


\subsection{Magnetic Flux Density Characteristic}

Table 4 below shows the simulation of the magnetic flux density for all three coil pairs. The blue colour around the coil represents the air environment.

Table 4: The magnetic flux density norm for each coil pair

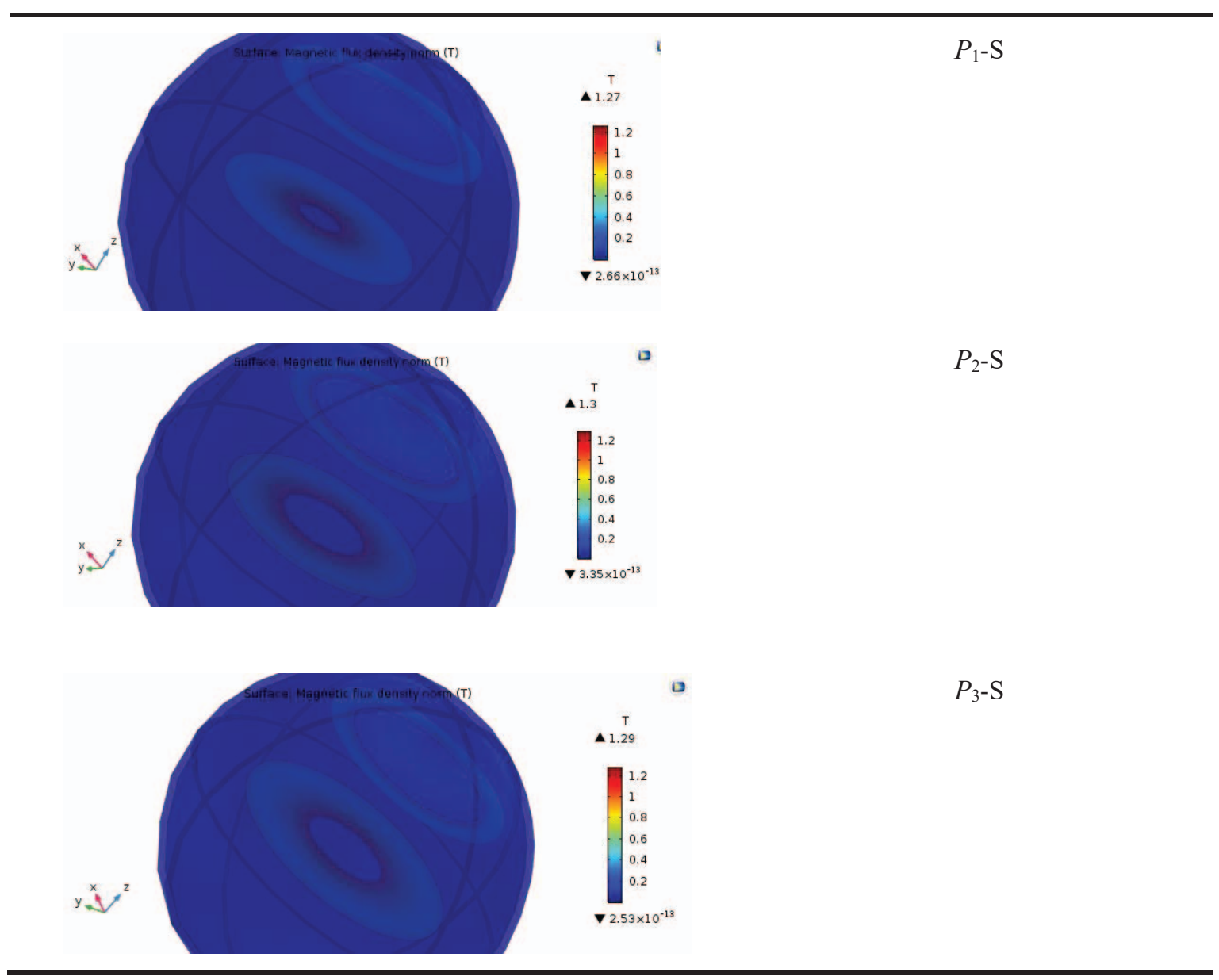

The simulation shows that the $P_{2}-\mathrm{S}$ coupling pair gives the highest magnetic flux density norm, which is $1.3 \mathrm{~T}$. The strengths of the magnetic flux density norms in descending order are $P_{2}>P_{3}>P_{1}$. Therefore, the $P_{2}$-S coil pair is chosen for use in EV charging since it has high strength of magnetic field and magnetic flux density norm between the two coils.

\subsection{Simulations Varying the Inner Diameter of $\boldsymbol{P}_{2}$ Coils}

In the previous simulation, $P_{2}$-S has been proven to provide the highest magnetic field norm and magnetic flux density. Therefore, in this section, the $P_{2}-\mathrm{S}$ design is further simulated to find the most suitable parameter for the primary coil. The inner diameter for the $P_{2}$ coil is varied between $12 \mathrm{~cm}, 16 \mathrm{~cm}$, and $20 \mathrm{~cm}$ while maintaining the outer diameter of $28 \mathrm{~cm}$. Table 5 shows the value of varying the $P_{2}$ inner diameter.

Table 6 shows the simulation results for the $P_{2}$ coil by varying the inner diameter of the primary coil. The parameter for the coil was shown in Table 1. From the simulation results, it can be seen that the magnetic field behaviour for larger inner diameter of primary coil is higher. It can be seen $P_{2 \mathrm{c}} \mathrm{S}$ has more arrows compared to the other two designs. 
Arrows inside the coil and air region indicate the amount of magnetic field flow between the two coils. The sphere line in this simulation represents the air region.

Furthermore, as the magnetic field arrow increases, the magnetic flux density value also increases. As can be seen from Table $6, P_{2 \mathrm{c}}$-S has the highest magnetic flux density value of $1.67 \mathrm{~T}$. Therefore, $P_{2 \mathrm{c}}-\mathrm{S}$ will produce the highest power transfer between primary and secondary coils.

Table 5: Geometry parameters varying the inner diameter for $P_{2}$ coils

\begin{tabular}{ccc}
\hline Coil & $\boldsymbol{D}_{\text {out }}(\mathbf{c m})$ & $\boldsymbol{D}_{\text {in }}(\mathbf{c m})$ \\
\hline$S$ & 28 & 21.4 \\
$P_{2 a}$ & 28 & 12 \\
$P_{2 b}$ & 28 & 16 \\
$P_{2 c}$ & 28 & 20 \\
\hline
\end{tabular}

Table 6: Simulation results varying the inner diameter for $P_{2}$ coils

Coil pair Magnetic field behaviour


According to the International Commission on Non-Ionizing Radiation Protection (ICNIRP) 2010 guidelines, the reference level for magnetic fields is $27 \mu \mathrm{T}$ for frequencies between $3 \mathrm{kHz}$ to $10 \mathrm{MHz}[16,17]$. However, the value achieved from this simulation is in the range of $1.3 \mathrm{~T}$ to $1.67 \mathrm{~T}$ and it exceeds the reference level. Therefore, it shows that several improvements need to be done before it can be used by the public. High magnetic flux density is useful to increase the effectiveness of power transfer. But, if the value exceeds the maximum value set by ICNIRP, it might be harmful for the public.

\section{CONCLUSION}

This paper has successfully investigated the effect of unsymmetrical pad couplers on the magnetic flux density in air environment. Three pairs of unsymmetrical pad couplers were designed and simulated using COMSOL Multiphysics software in order to analyse the magnetic properties for each pair. The primary coil is varied by the diameter of the coil while secondary coil's parameter is kept constant. From the results, similar values of the coil's outer diameter will give a strong magnetic field and magnetic flux density. The simulation done in COMSOL Multiphysics shows that the second coil pair $\left(P_{2}-\mathrm{S}\right)$ that has an outer diameter of $28 \mathrm{~cm}$ has the highest magnetic field and magnetic flux density norm, which is $1.0 \times 10^{6} \mathrm{~A} / \mathrm{m}$ and $1.3 \mathrm{~T}$, respectively. Another simulation was done to find the best inner diameter of the primary coil $\left(P_{2}\right)$. The results show that $P_{2 c}-\mathrm{S}$ gives the highest magnetic flux density of $1.67 \mathrm{~T}$. Therefore, high magnetic field and magnetic flux density will provide high power transfer between the primary and secondary coils. Thus, the $P_{2 c}-\mathrm{S}$ coil pair is chosen for use in EV wireless charging. However, further research can explore a coil pair that is safe for use by the public and obeys the standards given by ICNIRP.

\section{ACKNOWLEDGEMENT}

This work was partially supported by Ministry of Higher Education Malaysia (Kementerian Pendidikan Tinggi) under Fundamental Research Grant Scheme (FRGS) number FRGS17-038-0604.

\section{REFERENCES}

[1] K. Aditya, V. K. Sood, and S. S. Williamson. (2017) Magnetic characterization of unsymmetrical coil pairs using archimedean spirals for wider misalignment tolerance in ipt systems. IEEE Transaction on Transportation Electrification, 3(2): 454-463.

[2] R. Bosshard and J. W. Kolar. (2016) Inductive Power Transfer for Electric Vehicle Charging. IEEE Power Electronics Magazine: 22-30.

[3] Malaysian Green Technology Corporation "Low Carbon Mobility" [https://www.greentechmalaysia.my/services/low-carbon-mobility/]

[4] S. Yusoff, L. De Lillo, P. Zanchetta, and P. Wheeler. (2012) Predictive Control of a direct $\mathrm{AC} / \mathrm{AC}$ matrix converter power supply under non-linear load conditions. 15th International Power Electronics and Motion Control Conference Expo. EPE-PEMC 2012 ECCE Europe: $1-6$.

[5] S. Yusoff, L. De Lillo, P. Zanchetta, P. Wheeler, P. Cortés, and J. Rodríguez. (2012) Predictive control of a direct AC/AC matrix converter for power supply applications. 6th IET International Conference on Power Electronics, Machines and Drives (PEMD 2012): A92A92.

[6] P. S. R. Nayak and D. Kishan. (2018) Performance analysis of series/parallel and dual side LCC compensation topologies of inductive power transfer for EV battery charging system. Front. Energy: 1-14. https://doi.org/10.1007/s11708-018-0549-z

[7] C. Liu, C. Jiang, C. Qiu. (2017) Overview of Coil Designs for Wireless Charging of Electric 
Vehicle. IEEE PELS Workshop on Emerging Technologies: Wireless Power Transfer (WoW): 15-18.

[8] A. Ahmad, M. S. Alam, S. Member, and R. Chabaan. (2018) A Comprehensive Review of Wireless Charging Technologies for Electric Vehicles. IEEE Transaction on Transportation Electrification, 4(1): 38-63.

[9] M. Mohammad and S. Choi. (2018) Optimization of ferrite core to reduce the core loss in double-D pad of wireless charging system for electric vehicles. Conference Proceedings IEEE Applied Power Electronics Conference and Exposition (APEC): 1350-1356.

[10] A. Tejeda, C. Carretero, J. T. Boys, and G. A. Covic. (2017) Ferrite-Less Circular Pad with Controlled Flux Cancelation for EV Wireless Charging. IEEE Transactions on Power Electronics, 32(11): 8349-8359.

[11] M. Budhia, G. Covic, and J. Boys. (2010) A new IPT magnetic coupler for electric vehicle charging systems. IECON Proceedings- Industrial Electronics Conference: 2487-2492.

[12] W. Chen, C. Liu, C. H. T. Lee, and Z. Shan. (2016) Cost-effectiveness comparison of coupler designs of wireless power transfer for electric vehicle dynamic charging. Energies Journal: 113.

[13] S. Wang, Y. Guo, and D. Dorrell. (2017) Analysis of Rectangular EV Inductive Charging Coupler. 12th IEEE Conference Industrial Electronics and Applications: 285-291.

[14] L. Xiang, Y. Sun, Z. Ye, Z. Wang, and S. Zhou. (2016) Combined primary coupler design and control for EV dynamic wireless charging system. IEEE PELS Workshop on Emerging Technologies: Wireless Power, WoW 2016: 174-179.

[15] M. Budhia, S. Member, J. T. Boys, G. A. Covic, and S. Member. (2013) Development of a Single-Sided FluxMagnetic Coupler for Electric Vehicle IPT Charging Systems. IEEE Transactions on Industrial Electronics, 60(1): 318-328.

[16] S. Li and C. C. Mi. (2014) Wireless Power Transfer for Electric Vehicle Applications. IEEE Journal of Emerging and Selected Topics in Power Electronics, 3(1): 4-17.

[17] K. A. Grajski, R. Tseng, and C. Wheatley. (2012) Loosely-Coupled Wireless Power Transfer: Physics, Circuits, Standards. IEEE MTT-S International: 9-14. 